\title{
Stimulating research on childhood adversities, borderline personality disorder, and complex post-traumatic stress disorder
}

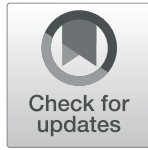

Annegret Krause-Utz ${ }^{1,2}$

\begin{abstract}
Traumatic events of a long-lasting invasive, primarily interpersonal nature (e.g., childhood abuse, intimate partner violence) can have wide-ranging consequences across various life domains. This involves an increased risk of developing mental disorders, such as (complex) post-traumatic stress (PTSD, CPTSD) and borderline personality disorder (BPD). Both within and outside of these diagnostic boundaries, complex trauma has been associated with emotional dysregulation, dissociation, distrust, interpersonal problems, and maladaptive coping behaviours, such as self-harm and suicidal behaviour. Knowledge on the devastating consequences of complex trauma has steadily increased. One of the remaining research questions is why some people develop certain psychopathological symptoms or disorders after complex trauma while others do not. Moreover, more research is needed to better understand how disorders such as BPD and CPTSD can be differentiated, both descriptively and empirically. This special issue brings together a collection of review articles and original research articles on this topic to stimulate further research in the field. Findings enhance the understanding of long-term consequences of childhood adversities and highlight important psychopathological mechanisms that may underlie an increased risk to develop certain mental disorders.
\end{abstract}

Keywords: Borderline personality disorder, Child sexual abuse, Complex trauma, Complex post-traumatic stress disorder, Post-traumatic stress disorder

\section{Introduction}

In the current literature, the term "complex trauma" is used to describe events of a long-lasting, invasive, and primarily interpersonal nature (e.g., severe child abuse and neglect by primary caregivers, intimate partner violence, rape, sex trafficking or sexual exploitation, medical trauma, war and refugee trauma, torture, and/or genocide), as opposed to singleincident trauma. It is still not entirely understood why some people develop certain psychopathological symptoms after traumatic events while others do not.

\section{Correspondence: a.d.krause@fsw.leidenuniv.nl}

${ }^{1}$ Institute of Psychology, Department of Clinical Psychology, Leiden University, Leiden, The Netherlands

¿Leiden Institute for Brain and Cognition, Leiden University, Leiden, The Netherlands
Experiencing traumatic events is not uncommon. In a large representative sample of 68894 adults from 24 countries, over $70 \%$ of respondents reported a traumatic event $[1,2]$. Approximately 3.9\%-5.6\% of traumaexposed individuals develop post-traumatic stress disorder (PTSD) [3], which is characterized by traumatic re-experiencing, avoidance of traumatic reminders, and hypervigilance $[4,5]$.

In 2018 , the $11^{\text {th }}$ International Classification of Diseases (ICD-11) introduced the diagnosis of complex post-traumatic stress disorder (CPTSD) as a "sibling diagnosis" of PTSD [4]. In addition to the three "classic" PTSD symptoms (traumatic re-experiencing, avoidance, hypervigilance), CPTSD is characterized by symptoms in three domains of disturbances in self-organization

(c) The Author(s). 2021 Open Access This article is licensed under a Creative Commons Attribution 4.0 International License, which permits use, sharing, adaptation, distribution and reproduction in any medium or format, as long as you give appropriate credit to the original author(s) and the source, provide a link to the Creative Commons licence, and indicate if changes were made. The images or other third party material in this article are included in the article's Creative Commons licence, unless indicated otherwise in a credit line to the material. If material is not included in the article's Creative Commons licence and your intended use is not permitted by statutory regulation or exceeds the permitted use, you will need to obtain permission directly from the copyright holder. To view a copy of this licence, visit http://creativecommons.org/licenses/by/4.0/ The Creative Commons Public Domain Dedication waiver (http://creativecommons.org/publicdomain/zero/1.0/) applies to the data made available in this article, unless otherwise stated in a credit line to the data. 
(DSO): 1) emotional dysregulation (e.g., problems in self-soothing and decreased stress tolerance), 2) interpersonal problems (e.g., avoidance of relationships), and 3) a negative self-concept (e.g., beliefs about oneself as being a failure) [4]. Since the publication of the CPTSD definition, research on this new diagnosis has steadily increased. While consensus regarding the validity of the CPTSD diagnosis is still lacking, there is growing evidence that CPTSD detects a distinct group of individuals with more severe impairment, who were exposed to multiple forms of trauma [6-8], mostly of an interpersonal nature $[9,10]$. Empirical studies further supported the validity of the 6 -factor symptom structure of CPTSD and its distinction from PTSD [6]. At the same time, researchers have raised the question whether CPTSD is indicative of a more severe form of psychological distress after trauma rather than a disparate constellation of symptoms (e.g., [11, 12]. The article by Andreas Maercker [13] gives a comprehensive overview of the development of the CPTSD diagnosis and highlights the growing attention to this research topic.

One of the remaining research questions is how CPTS $\mathrm{D}$ can be differentiated from borderline personality disorder (BPD), both descriptively and empirically. There is considerable symptom overlap, which has been addressed by a growing number of studies (e.g., [11, 1417]. BPD is characterized by a marked instability in affect, cognitions, behaviour and interpersonal relationships [5]. Current conceptualizations propose that three core domains underlie the complexity and heterogeneity of BPD symptoms: emotion dysregulation including stress-related impulsivity (maladaptive coping behaviours, such as self-harm and suicidal attempts), disturbed self-image, and interpersonal disturbances [18]. Unlike CPTSD, the diagnosis of BPD does not require an index traumatic event. However, individuals with BPD often report a history of severe abuse and neglect, and rates of childhood trauma are higher than in other psychiatric conditions $[19,20]$.

In their review article, Julian D. Ford and Christine A. Courtois provide a comprehensive overview over the relationship and differences between CPTSD and BPD. Their article summarizes recent findings on prevalence and comorbidity, clinical phenomenology, association with traumatic antecedents, psychobiology, and psychotherapeutic treatment of the two disorders.

Thereby, the authors provide a conceptual framework which will stimulate further research on the topic.

Research articles, included in this special issue, shed more light on the consequences of childhood adversities. Seitz and colleagues [21] used eye-tracking to investigate hypersensitivity to negative, potentially threatening interpersonal cues in BPD and its association with adverse childhood experiences. Findings point towards a childhood trauma-related anger bias and a visual hypervigilance towards the eyes of facial expressions in patients with BPD. Future studies should shed light on the remaining question whether these findings are specific for BPD or related to a history of childhood abuse and neglect in a trans-diagnostic manner.

The study by Hepp and colleagues [22] tested whether individuals who experienced childhood abuse and neglect show higher levels of distrust and perceived threat. Participants played two rounds of a hypothetical distrust game and an emotion rating task with angry, fearful, and happy facial expressions. Results suggest higher levels of distrust and a weaker decrease in distrust following positive feedback in individuals with childhood trauma.

Two studies in this article collection focused on child sexual abuse (CSA). Collin-Vézina and colleagues [23] explored the associations between CSA and non-suicidal and suicidal self-injurious thoughts and behaviors in relation to CSA disclosure experience. This qualitative study highlights the reciprocal influences between CSA disclosure and maladaptive coping behaviors as an attempt to seek help, which has important clinical implications. The study by Krause-Utz and colleagues [24] revealed a significant association between self-reported CSA and sexual revictimization in adult intimate relationships. Borderline personality features, maladaptive cognitive coping styles (e.g., self-blame, rumination) and dissociation were found to be important factors in this relationship.

Deuter and colleagues [25] investigated testosterone reactivity to an acute psychosocial stressor (Trier Social Stress Test, TSST) in women with BPD, PTSD, both disorders, and healthy control. The authors found an increase in testosterone after acute stress exposure across all groups, independent of BPD or PTSD status, and discuss possible explanations for this finding.

All in all, this article collection highlights the growing attention to the wide-ranging consequences of complex trauma. More research is needed to understand the inter-relationships of PTSD, CPTSD, and BPD as well as differences between these diagnoses.

\section{Acknowledgements \\ Not applicable.}

Author's contributions

AKU has designed and written the manuscript. The author(s) read and approved the final manuscript.

Funding

Not applicable.

Availability of data and materials Not applicable. 


\section{Declarations}

Ethics approval and consent to participate

Not applicable.

\section{Consent for publication}

Not applicable.

\section{Competing interests}

None.

Received: 18 March 2021 Accepted: 23 March 2021

Published online: 30 March 2021

\section{References}

1. Benjet C, Bromet E, Karam EG, Kessler RC, McLaughlin KA, Ruscio AM, et al. The epidemiology of traumatic event exposure worldwide: results from the world mental health survey consortium. Psychol Med. 2016;46(2):327-43. https://doi.org/10.1017/S0033291715001981.

2. Kessler RC, Aguilar-Gaxiola S, Alonso J, Benjet C, Bromet EJ, Cardoso G, et al. Trauma and PTSD in the WHO world mental health surveys. Eur J Psychotraumatol. 2017;8(sup5):1353383.

3. Koenen KC, Ratanatharathorn A, Ng L, McLaughlin KA, Bromet EJ, Stein DJ, et al. Posttraumatic stress disorder in the world mental health surveys. Psychol Med. 2017;47(13):2260-74. https://doi.org/10.1017/\$003329171 7000708.

4. World Health Organization (WHO). International classification of diseases for mortality and morbidity statistics (11th rev). https://icd.who.int/browse11/lm/en. 2018.

5. American Psychiatric Association, DSM-5 Task Force. Diagnostic and statistical manual of mental disorders: DSM-5 ${ }^{\text {TM }}$ (5th ed.). American Psychiatric Publishing, Inc; 2013 https://doi.org/10.1176/appi.books. 9780890425596.

6. Brewin CR, Cloitre M, Hyland P, Shevlin M, Maercker A, Bryant RA, et al. A review of current evidence regarding the ICD-11 proposals for diagnosing PTSD and complex PTSD. Clin Psychol Rev. 2017;58:1-15. https://doi.org/1 0.1016/j.cpr.2017.09.001.

7. Cloitre M, Garvert DW, Weiss B, Carlson EB, Bryant RA. Distinguishing PTSD, complex PTSD, and borderline personality disorder: a latent class analysis. Eur J Psychotraumatol. 2014;5(1):25097. https://doi.org/10.3402/ejpt.v5.2 5097.

8. McBride O, Hyland P, Murphy J, Elklit A. Network analysis of posttraumatic stress experiences of adults seeking psychological treatment for childhood sexual abuse. J Trauma Stress. 2020;33(1):10-8. https://doi.org/10.1002/ jts.22381.

9. Hyland P, Shevlin M, Fyvie C, Cloitre M, Karatzias T. The relationship between ICD-11 PTSD, complex PTSD and dissociative experiences. J Trauma Dissoc. 2020;21(1):62-72. https://doi.org/10.1080/15299732.2019.1 675113.

10. Karatzias T, Hyland P, Bradley A, Cloitre M, Roberts NP, Bisson Jl, et al. Risk factors and comorbidity of ICD-11 PTSD and complex PTSD: findings from a trauma-exposed population based sample of adults in the United Kingdom. Depress Anxiety. 2019;36(9):887-94. https://doi.org/10.1002/da.22934.

11. Saraiya TC, Fitzpatrick S, Zumberg-Smith K, López-Castro T, E Back S, A Hien D. Social-emotional profiles of PTSD, complex PTSD, and borderline personality disorder among racially and ethnically diverse young adults: a latent class analysis. J Trauma Stress. 2021;34(1):56-68. https://doi.org/10.1 002/its.22590.

12. Wolf EJ, Miller MW, Kilpatrick D, Resnick HS, Badour CL, Marx BP, et al. ICD11 complex PTSD in U.S. national and veteran samples: prevalence and structural associations with PTSD. Clin Psychol Sci. 2015;3(2):215-29. https:// doi.org/10.1177/2167702614545480.

13. Maercker A. Development of the new CPTSD diagnosis for ICD-11. Borderline Personal Disord Emot Dysregul. 2021;8(1):7. https://doi.org/10.11 86/s40479-021-00148-8.

14. Ford JD. Commentary on the special section on complex PTSD: still going strong after all these years. J Trauma Stress. 2019;32(6):877-80. https://doi. org/10.1002/jts.22474.

15. Jowett S, Karatzias T, Shevlin M, Albert I. Differentiating symptom profiles of ICD-11 PTSD, complex PTSD, and borderline personality disorder: a latent class analysis in a multiply traumatized sample. Personal Disord Theory Res Treat. 2020;11(1):36-45. https://doi.org/10.1037/per0000346.

16. Jowett $\mathrm{S}$, Karatzias $\mathrm{T}$, Albert I. Multiple and interpersonal trauma are risk factors for both post-traumatic stress disorder and borderline personality disorder: a systematic review on the traumatic backgrounds and clinical characteristics of comorbid post-traumatic stress disorder/borderline personality disorder groups versus single-disorder groups. Psychol Psychother Theory Res Pract. 2020;93(3):621-38.

17. Hyland P, Karatzias T, Shevlin M, Cloitre M. Examining the discriminant validity of complex posttraumatic stress disorder and borderline personality disorder symptoms: results from a United Kingdom population sample. J Trauma Stress. 2019;32(6):855-63. https://doi.org/10.1002/jts.22444.

18. Bohus M, Stoffers-Winterling J, Sharp C, Krause-Utz A, Schmahl C, Lieb K Borderline Personality Disorder. 2021 accepted for publication pending reviews;

19. Porter C, Palmier-Claus J, Branitsky A, Mansell W, Warwick H, Varese F. Childhood adversity and borderline personality disorder: a meta-analysis. Acta Psychiatr Scand. 2020;141(1):6-20. https://doi.org/10.1111/acps.13118.

20. Kleindienst N, Vonderlin R, Bohus M, Lis S. Childhood adversity and borderline personality disorder. Analyses complementing the meta-analysis by Porter et al. (2020). Acta Psychiatr Scand. 2021;143(2):183-4. https://doi. org/10.1111/acps.13256.

21. Seitz Kl, Leitenstorfer J, Krauch M, Hillmann K, Boll S, Ueltzhoeffer K, et al. An eye-tracking study of interpersonal threat sensitivity and adverse childhood experiences in borderline personality disorder. Borderline Personal Disord Emot Dysregul. 2021;8(1):2. https://doi.org/10.1186/s40479-020-00141-7.

22. Hepp J, Schmitz SE, Urbild J, Zauner K, Niedtfeld I. Childhood maltreatment is associated with distrust and negatively biased emotion processing. Borderline Personal Disord Emot Dysregul. 2021;8(1):5. https://doi.org/10.11 86/s40479-020-00143-5.

23. Collin-Vézina $D$, De La Sablonnière-Griffin $M$, Sivagurunathan $M$, Lateef $R$, Alaggia R, McElvaney R, et al. "How many times did I not want to live a life because of him": the complex connections between child sexual abuse, disclosure, and self-injurious thoughts and behaviors. Borderline Personal Disord Emot Dysregul. 2021;8(1):1.

24. Krause-Utz A, Dierick T, Josef T, Chatzak E, Hoogenboom AW, Elzinga BM. Linking experiences of child sexual abuse to adult sexual intimate partner violence: the role of borderline personality features, maladaptive cognitive coping, and dissociation. BPDED. https://doi.org/10.1186/s40479-021-00150-0.

25. Deuter CE, Duesenberg M, Hellmann-Regen J, Metz S, Roepke S, Wolf OT, et al. Psychosocial stress increases testosterone in patients with borderline personality disorder, post-traumatic stress disorder and healthy participants. Borderline Personal Disord Emot Dysregul. 2021;8(1):3. https://doi.org/10.11 86/s40479-021-00145-x.

\section{Publisher's Note}

Springer Nature remains neutral with regard to jurisdictional claims in published maps and institutional affiliations.

Ready to submit your research? Choose BMC and benefit from:

- fast, convenient online submission

- thorough peer review by experienced researchers in your field

- rapid publication on acceptance

- support for research data, including large and complex data types

- gold Open Access which fosters wider collaboration and increased citations

- maximum visibility for your research: over $100 \mathrm{M}$ website views per year

At $\mathrm{BMC}$, research is always in progress.

Learn more biomedcentral.com/submission 